\title{
Cost-Effectiveness Analyses, Costs and Resource Use, and Health-Related Quality of Life in Patients with Follicular or Marginal Zone Lymphoma: Systematic Reviews
}

\author{
Neerav Monga ${ }^{1}$. Jamie Garside ${ }^{2}$ - Binu Gurung ${ }^{3}$. Joan Quigley ${ }^{3}$. Peter O'Donovan ${ }^{3}$. Christoph Tapprich ${ }^{4}$. \\ Loretta Nastoupil $\left.\right|^{5} \cdot$ Catherine Thieblemont $^{6} \cdot$ Christina Loefgren $^{7}$
}

Published online: 21 March 2020

(c) The Author(s) 2020

\begin{abstract}
Background Follicular lymphoma (FL) and marginal zone lymphoma (MZL) are types of indolent non-Hodgkin lymphoma (NHL) that develop in the B lymphocytes (also known as B cells).

Objective The aim of this study was to conduct a comprehensive review of studies relating to cost effectiveness, costs and resource use, and health-related quality of life (HRQoL) in patients with FL or MZL.

Methods Three separate systematic reviews were conducted to identify all published evidence on cost effectiveness, costs and resource use, and HRQoL between 2007 and March 2017 using the MEDLINE ${ }^{\circledR}$, MEDLINE in-process, E-pubs ahead of print $\left(\right.$ Ovid $\left.\mathrm{SP}^{\circledR}\right)$, Embase $\left(\right.$ Ovid $\left.\mathrm{SP}^{\circledR}\right)$, NHS EED, and EconLit databases. Select congress proceedings were also searched. Two systematic reviewers independently reviewed titles, abstracts, and full papers against eligibility criteria. Relevant data were extracted into bespoke data extraction templates (DETs) by a single systematic reviewer; these data were then validated for accuracy by a second reviewer against clean copies of the relevant publications.

Results A total of 25 cost-effectiveness studies (24 in FL; 1 in FL and MZL) met the eligibility criteria. Markov models were the most utilised cost-effectiveness model. US FL studies reported an incremental cost-effectiveness ratio (ICER) of $\$ 28,565 / \mathrm{QALY}$ for first-line rituximab-cyclophosphamide, vincristine, and prednisone (R-CVP) versus CVP, and $\$ 43,000$ / QALY for second-line obinutuzumab plus bendamustine $(\mathrm{G}+\mathrm{B})$ followed by $\mathrm{G}$ maintenance versus $\mathrm{B}$. In the UK, ICERs were £1529-10,834/quality-adjusted life-year (QALY) for first-line rituximab + chemotherapy versus chemotherapy, £27,988/ QALY for second-line G + B + G-maintenance versus B, and £62,653/QALY for second-line idelalisib versus chemotherapy and/or rituximab. Five costs/resource use and four HRQoL studies were identified in FL, and none in MZL. US mean lifetime costs in first-line patients ranged from $\$ 108,000$ (rituximab) to $\$ 130,300$ (rituximab-cyclophosphamide, doxorubicin hydrochloride, vincristine and prednisolone [CHOP]), and from $£ 2185$ (watch-and-wait) to $£ 17,054$ (chemotherapy) in the UK. In a multinational study, more rituximab-refractory patients receiving $\mathrm{G}+\mathrm{B}+\mathrm{G}$-maintenance reported a meaningful improvement in total FACT-Lym scores compared with patients receiving B. In the UK, total FACT-Lym scores were meaningfully higher for newly diagnosed patients compared with patients with progression (136.04 vs. 109.7).

Conclusions and Relevance We found a small body of evidence of quality of life, and potentially cost-effective treatment options for FL; however, no evidence was reported on MZL specifically. The significant data gaps in knowledge in these diseases demonstrate a marked need for further studies.
\end{abstract}

\section{Introduction}

Electronic supplementary material The online version of this article (https://doi.org/10.1007/s41669-020-00204-z) contains supplementary material, which is available to authorized users.

Neerav Monga

nmonga@its.jnj.com

Extended author information available on the last page of the article
Follicular lymphoma (FL) and marginal zone lymphoma (MZL) are types of indolent non-Hodgkin lymphoma (NHL) that develop in the B lymphocytes (also known as B cells) [1]. Initial treatment of indolent NHL often achieves tumour response and is successful. However, high rates of disease relapse result in repeated courses of chemotherapy characterised by shorter response periods between each relapse [2] 


\section{Key Points for Decision Makers}

The addition of rituximab to chemotherapy-based therapies, as well as rituximab maintenance, improved clinical outcomes in a cost-effective way.

Disease progression may be a driver of healthcare resource use, cost, and patient health-related quality of life, however further research is required to confirm this.

Despite treatments being available for patients with follicular lymphoma and marginal zone lymphoma, there is still an unmet need to slow disease progression and improve quality of life for patients.

With limited therapeutic options, novel treatments and combinations of novel treatments for FL and MZL have the potential to improve patient outcomes; however, to the authors' knowledge, there has never been a systematic review to identify the current cost-effectiveness evidence base for such regimens. Such a review would be necessary to not only consider the costs and benefits regimens may bring but also to understand the evolution in economic modelling in this area.

This study aims to describe the economic and health burden in patients with FL or MZL. The combined reporting of relevant economic and health outcomes appraisals (i.e. cost-effectiveness analyses [CEAs] and cost-utility analyses [CUAs]) can provide clinical insights and greater understanding of current evidence to improve overall efficiency in the decision-making process. Combined, the three systematic literature reviews (SLRs) summarise pertinent economic and burden information to help aid health care decision making.

\section{Methods}

Three separate SLRs were conducted to examine cost-effectiveness models, cost/resource use, and health-related quality of life (HRQoL) associated with treatments for FL and MZL. These SLRs followed validated methodologies [3-5] consistent with those outlined in the existing literature [6]. Eligibility criteria included adult patients with FL or MZL, treated with pharmacological interventions, palliative care (for cost/resource use), and no treatment (for cost/resource use and HRQoL), and study designs specific to the SLR, such as economic modelling publications, or reporting costs/ HRQoL data. Full eligibility criteria are provided in electronic supplementary Table 1.

All searches for published studies were conducted on 9 March 2017, from 2007 to 8 March 2017, using the
MEDLINE $^{\circledR}$, MEDLINE in-process, E-pubs ahead of print (Ovid SP ${ }^{\circledR}$ ), Embase (Ovid SP ${ }^{\circledR}$ ), NHS EED, and EconLit databases.

Search strategies were developed using published and tested search filters for economic and HRQoL studies, as well as combined free text and controlled vocabulary terms (Medical Subject Headings in MEDLINE and Emtree terms in Embase) for the population of interest. A single search strategy was used to identify studies of economic models and costs/resource use, and a separate search was conducted for HRQoL study identification. Relevant conference proceedings from 2015 to 2016 were also searched. Additional searches performed included website of health technology assessment (HTA) bodies using the HTA database (via OVID), Tufts Cost-Effectiveness Analysis registry, National Institute for Health and Care Excellence (NICE), Scottish Medicines Consortium (SMC), Canadian Agency for Drugs and Technologies in Health (CADTH), and the Pharmaceutical Benefit Advisory Committee. Full details of the PICO framework, inclusion/exclusion criteria, and full search strategy are provided in electronic supplementary Tables 1, 2 and 3.

Two systematic reviewers (BG and PO'D) independently reviewed titles, abstracts, and full papers against the eligibility criteria. Relevant data (including study design, methods, outcomes, conclusions) were extracted into bespoke DETs by a single systematic reviewer (PO'D); these data were then validated for accuracy by a second reviewer (BG) against clean copies of the relevant publications. Journal websites were cross-checked for errata and supplementary materials. An additional third reviewer (JQ) was used to resolve disagreements when needed. Preferred Reporting Items for Systematic Reviews and Meta-Analyses (PRISMA) diagrams for cost-effectiveness models, costs and resource use, and HRQoL studies are shown in electronic supplementary Fig. 9

\section{Results}

\subsection{Cost-Effectiveness Models/Analyses}

A total of 25 studies reporting on cost effectiveness were included in the review (Tables 1,2,3). Cost-effectiveness comparisons were reported using CUAs and CEAs in 14 studies. CUA alone was conducted in eight studies, CEA alone was conducted in two studies, and cost-minimisation analysis (CMA) was conducted separately in one study. Models and analyses were developed in the context of the UK (seven studies), USA (five studies), Canada (four studies), Australia (three studies), and Finland (two studies). There was one study each conducted in Russia, The Netherlands, Spain, and Sweden. The most commonly reported 


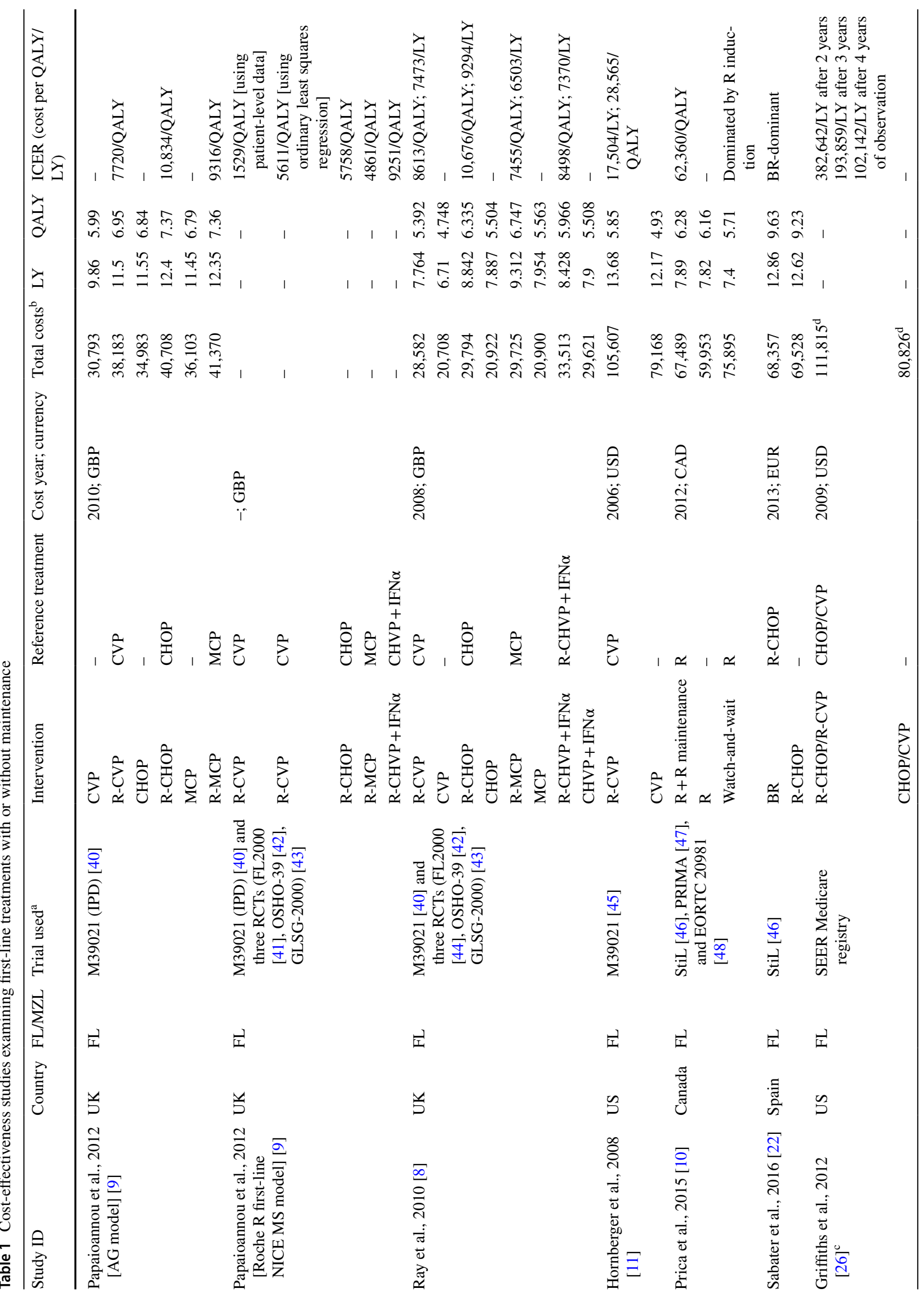


regimens were rituximab (R) based, either in monotherapy (12 studies either as first/second-line or maintenance) or as combination with cyclophosphamide, doxorubicin hydrochloride, vincristine and prednisolone (CHOP; nine studies either as first/second-line or maintenance). Other treatments investigated included bendamustine (B), CHEP (cyclophosphamide, etoposide, doxorubicin and prednisone), CVP (cyclophosphamide, vincristine and prednisone), cyclophosphamide (CTX), idelalisib (IDEL), interferon (IFN)- $\alpha$, MCP (mitoxantrone, chlorambucil and prednisone), and obinutuzumab (G). Electronic supplementary Table 8 summarises the general study characteristics utilising cost-effectiveness models/analyses.

\subsection{Model/Analysis Design Overview}

The cost effectiveness of first-line treatments was evaluated in eight studies (seven for FL, one for FL and MZL) [7-13], and nine studies reported cost-effectiveness of maintenance treatment [14-21]. Six studies were found to report cost effectiveness of treatments for relapsed/refractory $(R / R) F L$, while only three studies reported cost-effectiveness evidence for refractory FL. A Markov modelling approach, mainly depicting a three-state disease model (progression-free, progressive disease and death), was used in the majority of costeffectiveness publications $[8,11,18,20-25]$. Other analysis types used included cohort-based analysis [26], probabilistic decision analytic model [9], transitional state model [19], and a partitioned survival model [27]. No relevant structural differences were observed in the included models over the 10-year period this review encompassed. Time horizons ranged between 5 and 30 years, and cycle life ranged from 1 to 6 months. One abstract described differences in routes of treatment administration (subcutaneous vs. intravenous RR), but model characteristics were not described [7].

\subsection{Model/Analyses Results}

\subsubsection{First-Line Treatment}

First-line treatment model results are presented in Table 1. $\mathrm{R}+$ chemotherapy was cost effective in comparison with chemotherapy for the treatment of FL, as reported in UKbased studies. In particular, R-CVP versus CVP was projected to have an incremental cost-effectiveness ratio (ICER) ranging between $£ 1529$ /quality-adjusted life-year (QALY) gained and £8613/QALY gained (Great Britain pounds [GBP]; 2008) [8]. R-CHOP versus CHOP was projected to have an ICER ranging between $£ 5758 / \mathrm{QALY}$ gained [9] and $£ 10,834 /$ QALY gained (GBP; 2010) [9]. R-MCP versus MCP was projected to have an ICER ranging between $£ 4861 /$ QALY gained [9] and £9316/QALY gained (GBP; 2010) [9]. 


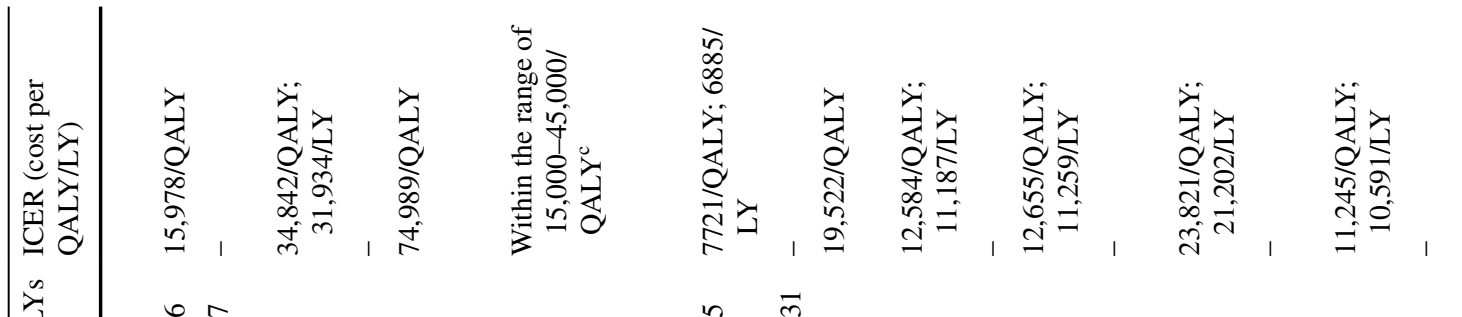

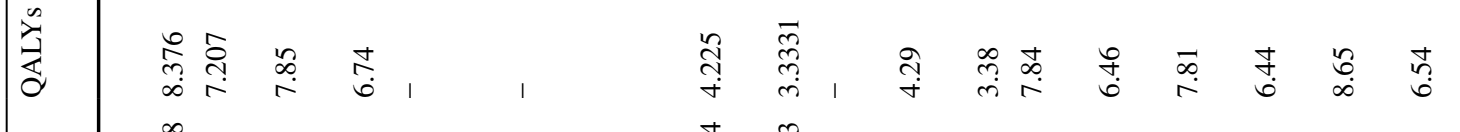

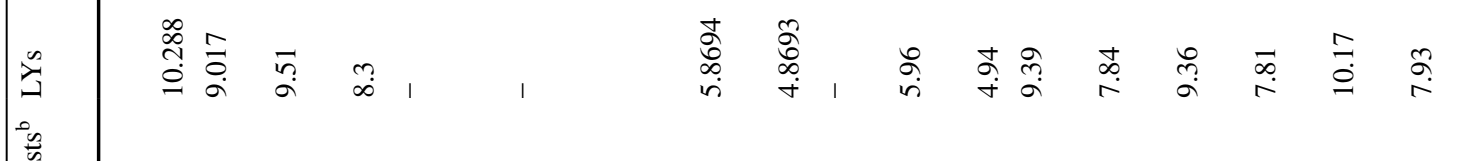

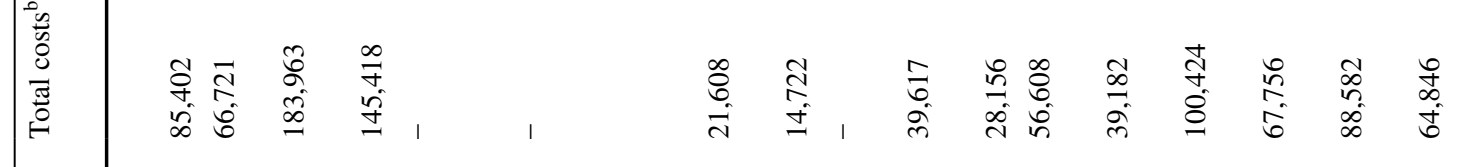

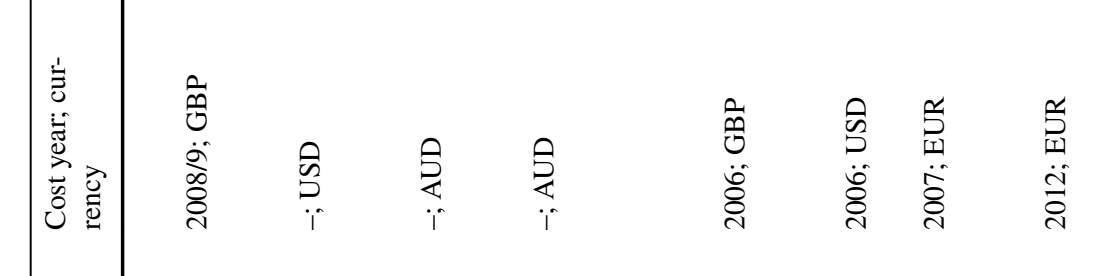

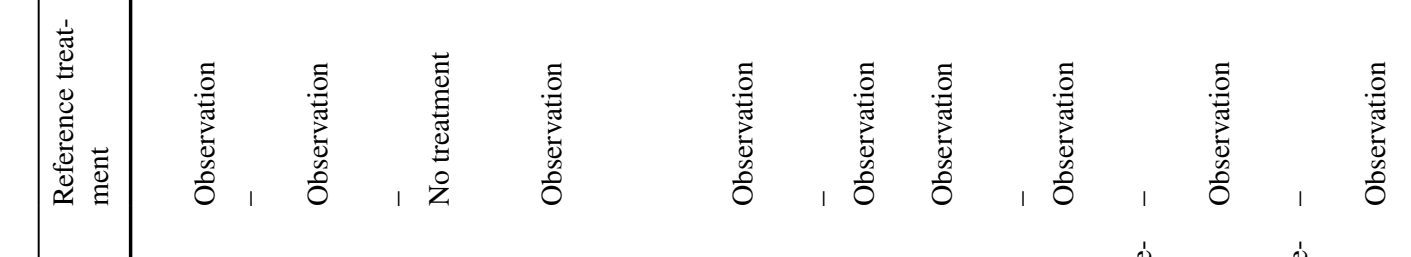

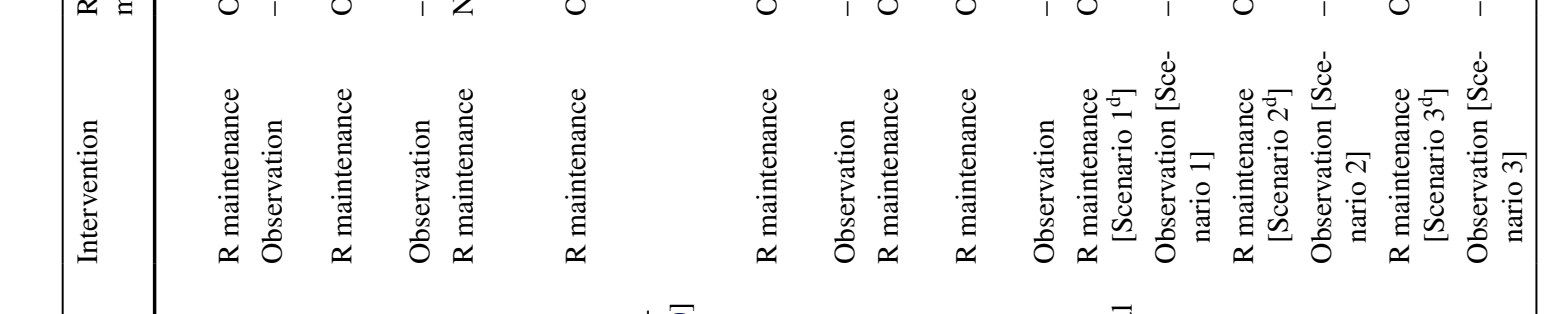

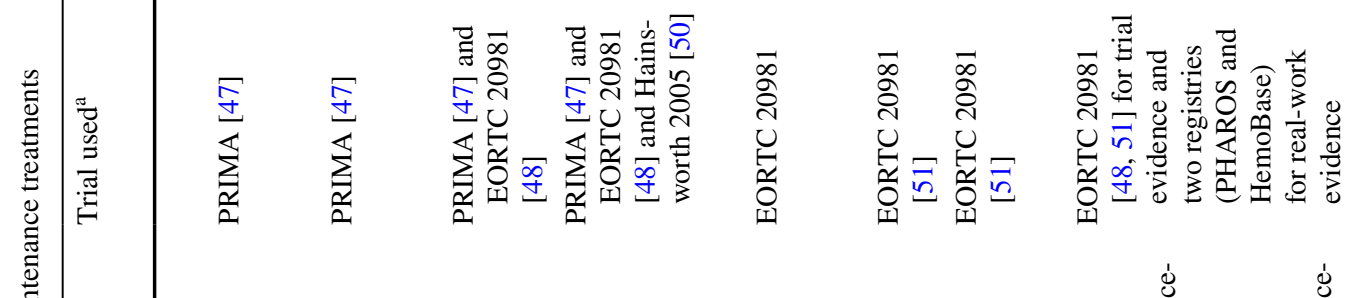

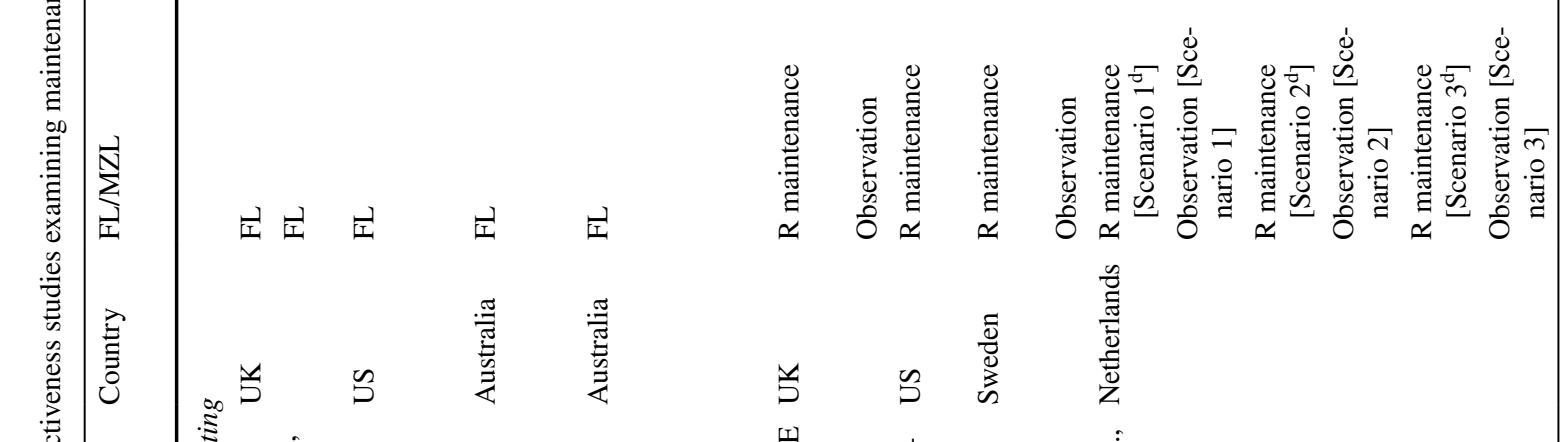

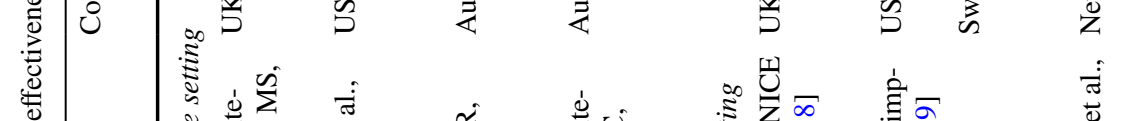

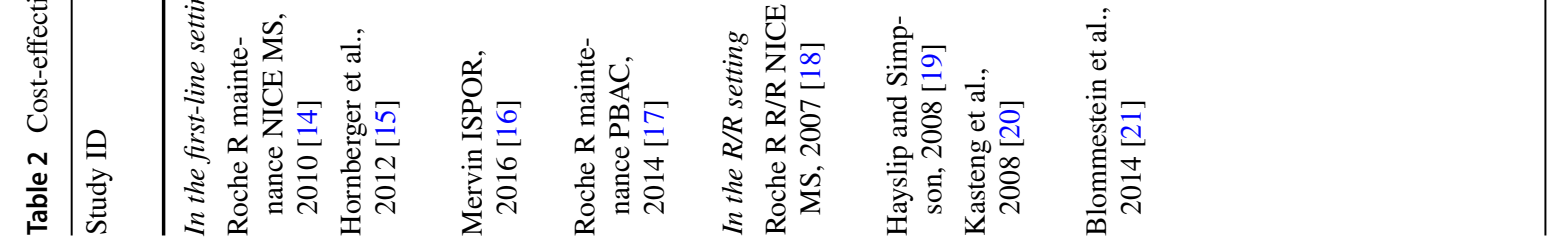




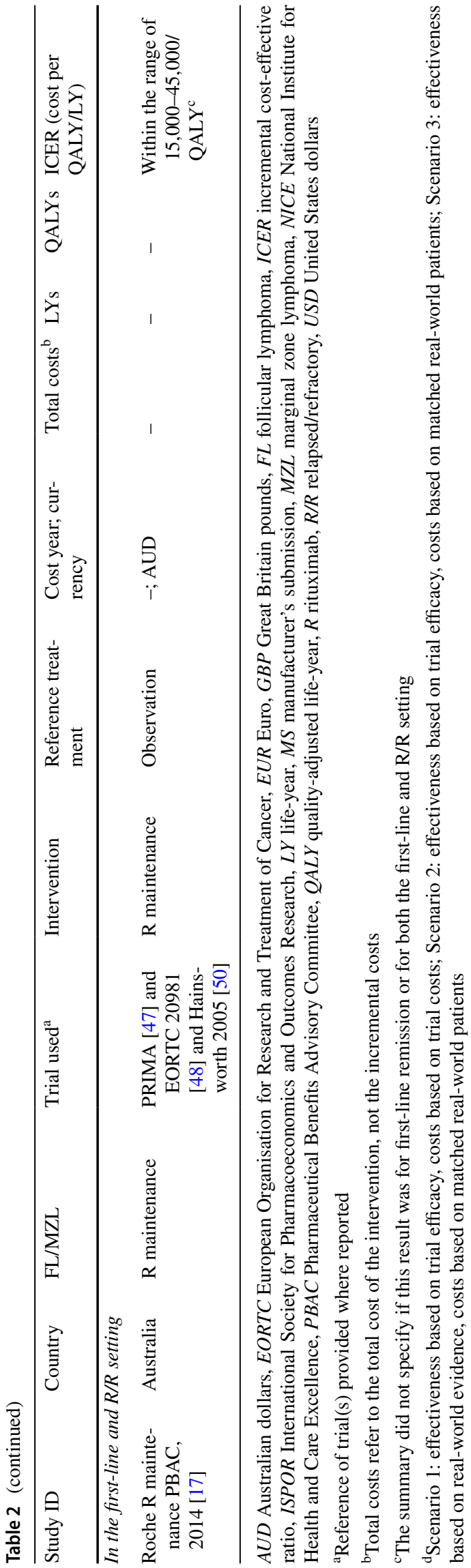

In Canada, an analysis evaluating first-line therapy with $\mathrm{R}$ with or without maintenance ( $\mathrm{R}$ induction vs. $\mathrm{R}$ induction $+\mathrm{R}$ maintenance) was projected to have an ICER of $\$ 62,360$ (Canadian dollars [CAD]; 2012) per QALY gained for FL [10], and R monotherapy was dominant over watchand-wait for FL [10]. Additionally, B + R versus R-CHOP was projected to have an ICER of $\$ 27,398 /$ QALY gained (CAD; 2012) for FL and \$10,012/QALY gained (CAD; 2012) for MZL [10].

In the US, R-CVP versus CVP followed a similar trend as the UK, with projected ICERs of \$28,565/QALY gained and \$17,504/life-year (LY) gained [11]. The projected ICER per LY gained improved annually (\$382,642/LY, \$193,859/ LY and \$102,142/LY 2, 3 and 4 years after observation, respectively) for $\mathrm{R}-\mathrm{CHOP} / \mathrm{R}-\mathrm{CVP}$ versus $\mathrm{CHOP} / \mathrm{CVP}$ in the US. The continued accrual of cumulative survival benefit of $\mathrm{R}$ throughout the observation periods, and cumulative cost being negligible post first-line treatment, were highlighted to result in a rapid decrease of ICER values over the observed years [26]. In Spanish studies, B + R was dominant over R-CHOP [10].

\subsubsection{First-Line Maintenance Treatment}

Maintenance treatment results are presented in Table 2. All data reported were for FL patients as no MZL cases were included. R maintenance was compared with watch and wait (or observation) in FL patients. In patients responding to first-line treatment, $\mathrm{R}$ maintenance had an ICER of $£ 15,978$ / QALY gained (GBP; 2008/2009) in the UK [14], \$34,842 (US dollars [USD]; year unspecified) in the US [15], and \$74,989/QALY gained (Australian dollars [AUD]; year unspecified) in Australia [16]. Another Australian study (Pharmaceutical Benefits Advisory Committee [PBAC] summary) reported an ICER between $\$ 15,000$ and $\$ 45,000 /$ QALY gained, but it was not specified if this was for a firstline or both first-line and R/R setting [28].

\subsubsection{Treatment for Relapsed and/or Refractory FL}

Treatments for relapsed and/or refractory FL model results are presented in Table 3. All data reported were for FL patients as no MZL cases were included. In the UK, $\mathrm{G}+\mathrm{B}+\mathrm{G}$ maintenance versus $\mathrm{R}+$ chemotherapy had an ICER of $£ 27,988 / \mathrm{Q} A L Y$ gained, R-CHOP + R maintenance versus CHOP $+\mathrm{R}$ maintenance had an ICER of $£ 16,749$ / QALY gained, and CHOP + R maintenance versus CHOP had an ICER of $£ 9076 /$ ALY gained. G + B + G maintenance versus $B$ had projected ICERs of \$62,833/QALY gained in Canada [23], \$43,000/QALY gained in the US [29], and \$45,000-\$75,000 in Australia [28]. In Finland, $\mathrm{R}-\mathrm{CHOP}+\mathrm{R}$ maintenance versus R-CHOP had an ICER of $€ 18,147 / \mathrm{Q} A L Y$ gained, R-CHOP + R maintenance versus 


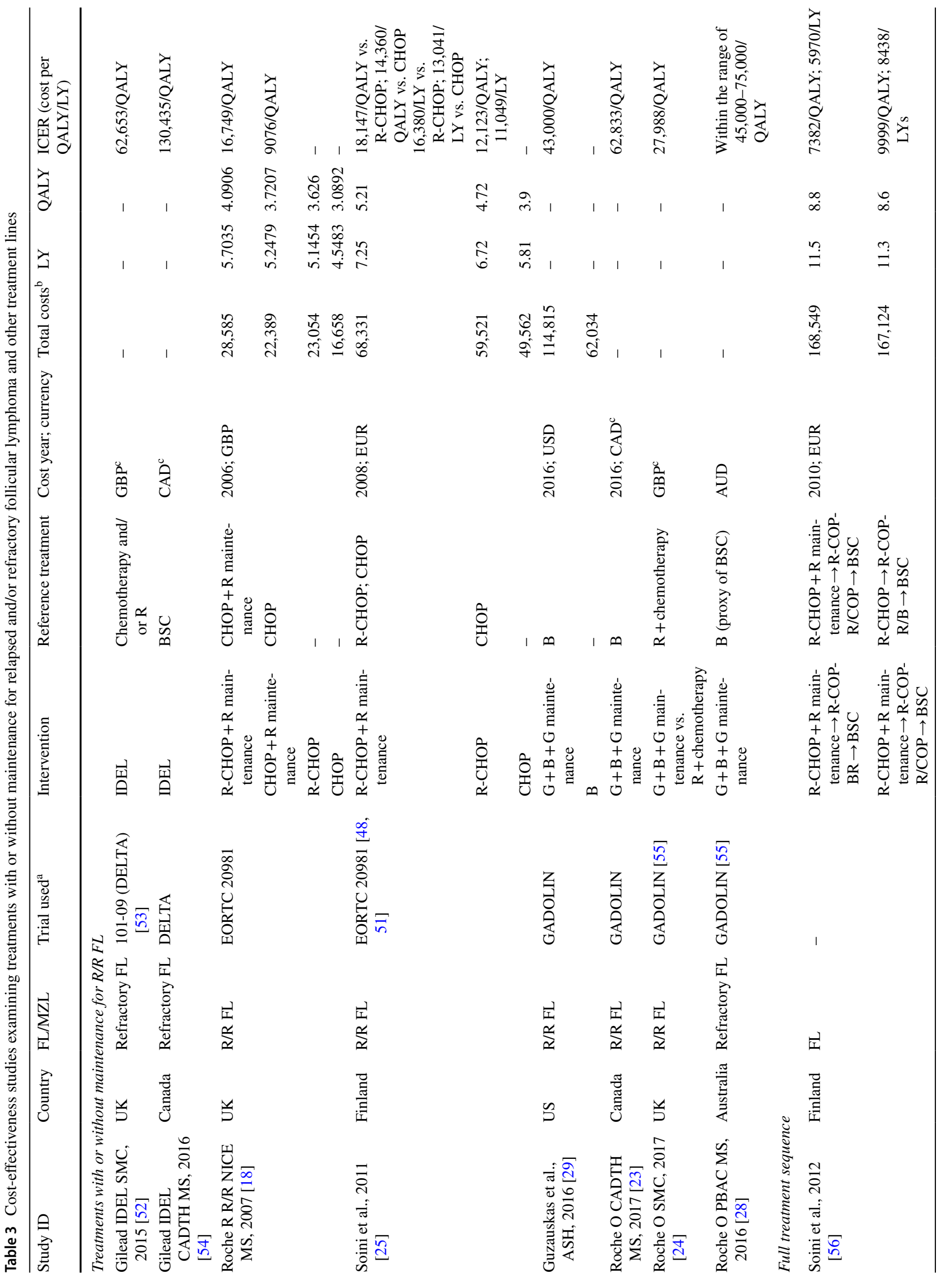




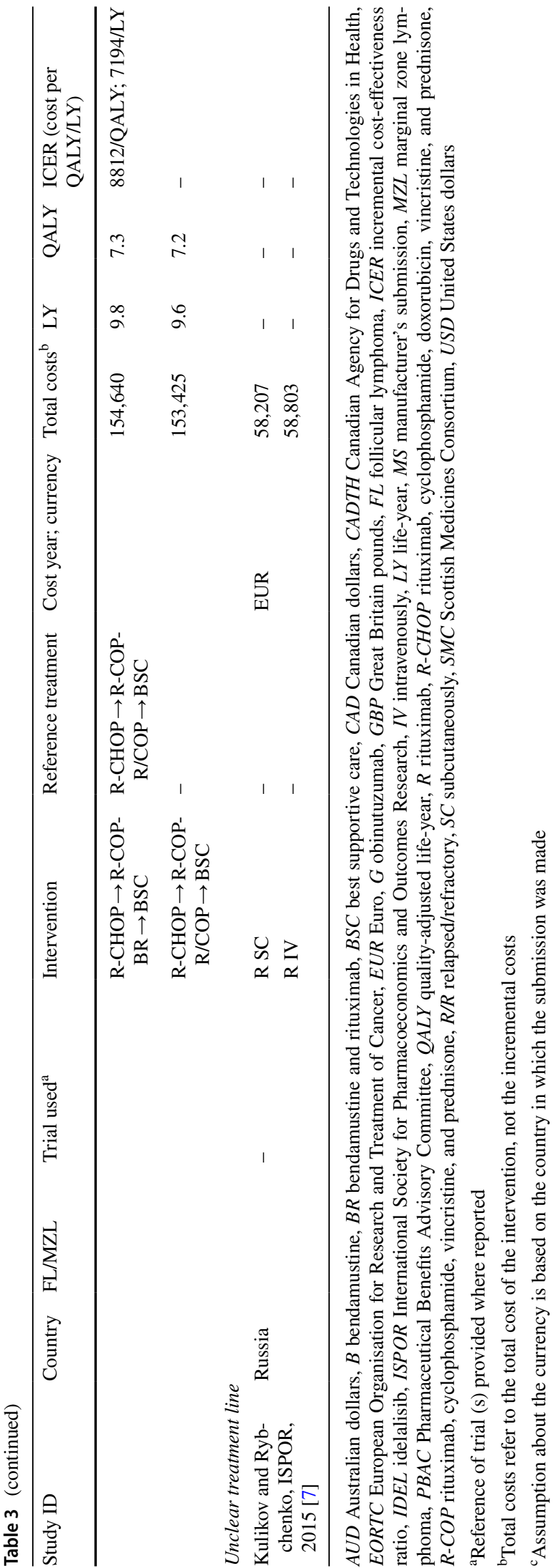

CHOP had an ICER of $€ 14,360 / \mathrm{Q} A L Y$ gained, and R-CHOP versus $C H O P$ had an ICER of $€ 12,123 / Q A L Y$ gained. IDEL versus chemotherapy and/or R had an ICER of $£ 62,653$ / QALY gained in the UK, while IDEL versus best supportive care had an ICER of \$130,435/QALY gained in Canada in patients with refractory FL.

\subsubsection{Relapsed/Refractory Maintenance Treatment}

For R/R settings in The Netherlands [21], ICERs were calculated for three scenarios looking specifically at $\mathrm{R}$ maintenance versus observation. The scenarios were (1) efficacy and costs based on trial data; (2) efficacy based on trial efficacy and costs based on matched real-world patients; and (3) real-world effectiveness based on real-world evidence (RWE) and costs based on matched real-world patients; the ICERs were $€ 11,245, € 12,655$ and $€ 23,821 / Q A L Y$ gained (EURO; 2012), respectively. The results are presented in Table 2.

\subsection{Costs/Resource Use}

Three studies and two abstracts in FL met the eligibility criteria for final inclusion. One study assessed patients who received prior treatment [30], while the other four included only treatment-naïve patients [26, 31-33]. Treatment regimens, when reported, all incorporated the use of $\mathrm{R}$ in monotherapy or combination. The time horizon ranged from 1 year [30] to a lifetime [32,33]. Studies were conducted from the health care payer perspective, when reported [30-32, 34].

Table 4 provides direct cost results, with direct drug and non-drug costs further depicted in electronic supplementary Table 5. Two studies $[32,33]$ reported the total mean cost over a lifetime. The reported lifetime costs from diagnosis until death for patients receiving R-CHOP, $\mathrm{R}+$ chemotherapy, and R alone were $\$ 108,000$ (USD; 2014), $\$ 114,800$, and $\$ 130,300$, respectively [32]. UK patients under a watch-and-wait strategy (£2185) and radiotherapy (£4651) were estimated to incur less costs than patients receiving chemotherapy $(£ 17,054)$ as an initial treatment [33]. Annual total mean costs for patients with disease progression were $\$ 30,890$, compared with $\$ 8704$ for patients without disease progression [30]. Indirect costs were not reported in any of the studies. One study [30] concluded that patients with disease progression experience more health care visits (chemotherapy, outpatients and acute care) and laboratory procedures than patients with stable disease.

\subsection{Health-Related Quality of Life}

HRQoL was evaluated in FL patients in two, multinational, phase III randomised trials $[35,36]$ and two 


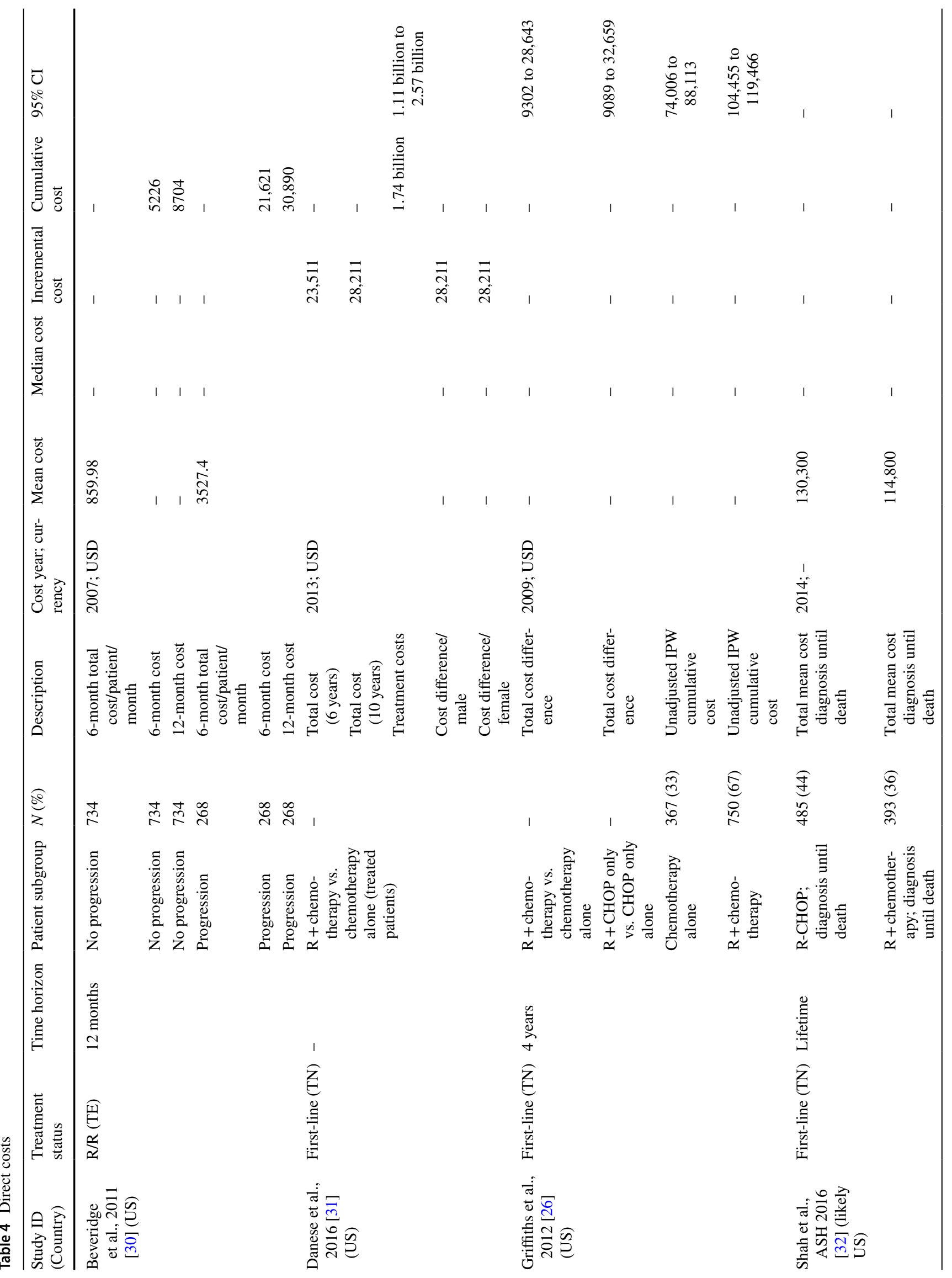




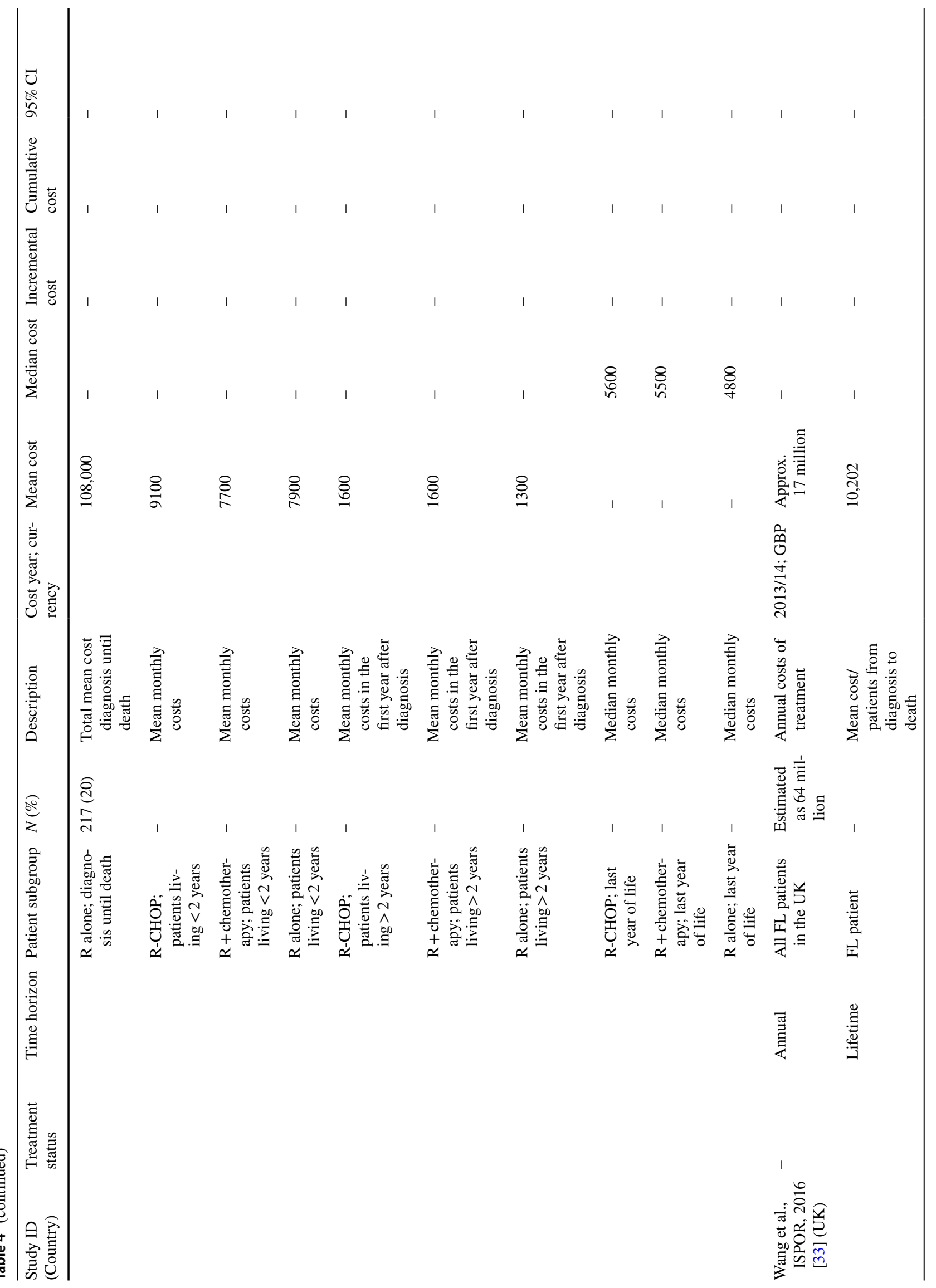


population-based studies [37, 38]. Population-based studies were conducted in The Netherlands [37] and the UK [38]. Relevant HRQoL findings were extracted (Table 5) and study characteristics are presented in electronic supplementary Table 7.

FACT-Lym, FACT-Lym-specific subscales, and the FACT-Lym Trial Outcome Index (TOI) were measured at three time points in the GADOLIN trial [35]; day 1 of cycle 5 of induction, 4-6 months post induction, and $8-12$ months post induction. Clinically meaningful differences were defined as $a \geq 7$-point increase in the total FACTLym score, $\geq 3$-point increase in the FACT-Lym-specific subscale, and $\geq 6$-point increase in the FACT-Lym TOI. At each time point reported, more patients receiving $\mathrm{G}+\mathrm{B}+\mathrm{G}$ maintenance (compared with B-treated patients) had clinically meaningful increases in all three HRQoL scores [35]. However, the authors noted there were no notable differences relating to treatment received in the average scores on the FACT-Lym questionnaire subscales at baseline, during the treatment period, and at follow-up [35].

FACT-Lym and TOI scores were reported for patients being treated with or without chemotherapy in the trial by Pettengell et al. [38]. Five disease states were examined (newly diagnosed active disease, active disease relapsed, partial remission, remission/complete remission, and disease-free) [38]. HRQoL scores were lower in patients who received chemotherapy compared with patients who were not treated with chemotherapy, although statistical significance was not reported. HRQoL scores were high in newly diagnosed active disease states [38]. Scores decreased upon entry into the active disease, relapsed stage, but increased with further disease remission, indicating that patientreported outcomes differed according to disease state [38].

In the PRIMA [36] trial, patients with non-progressing disease on observation had slightly better quality of life as reported by the EORTC-QLQ-C30 tool compared with those receiving $\mathrm{R}$ monotherapy, although statistics were not reported. In the trial by Oerlemans et al. [37], patients on a watch-and-wait treatment regimen experienced significantly and clinically meaningful higher fatigue than the general population, as determined by EORTC-QLC-C30.

\section{Discussion}

To the authors' knowledge, this is the first SLR performed to date that identifies economic and quality-of-life data for patients with FL or MZL. First, of the 25 included studies, there are several commonalities of note. The majority (18 of the 25 studies) of studies used a three health state Markov model structure with progression-free, progressive disease, and death. A model perspective was reported in 18 of the 25 studies; the majority of these adopted the perspective of 


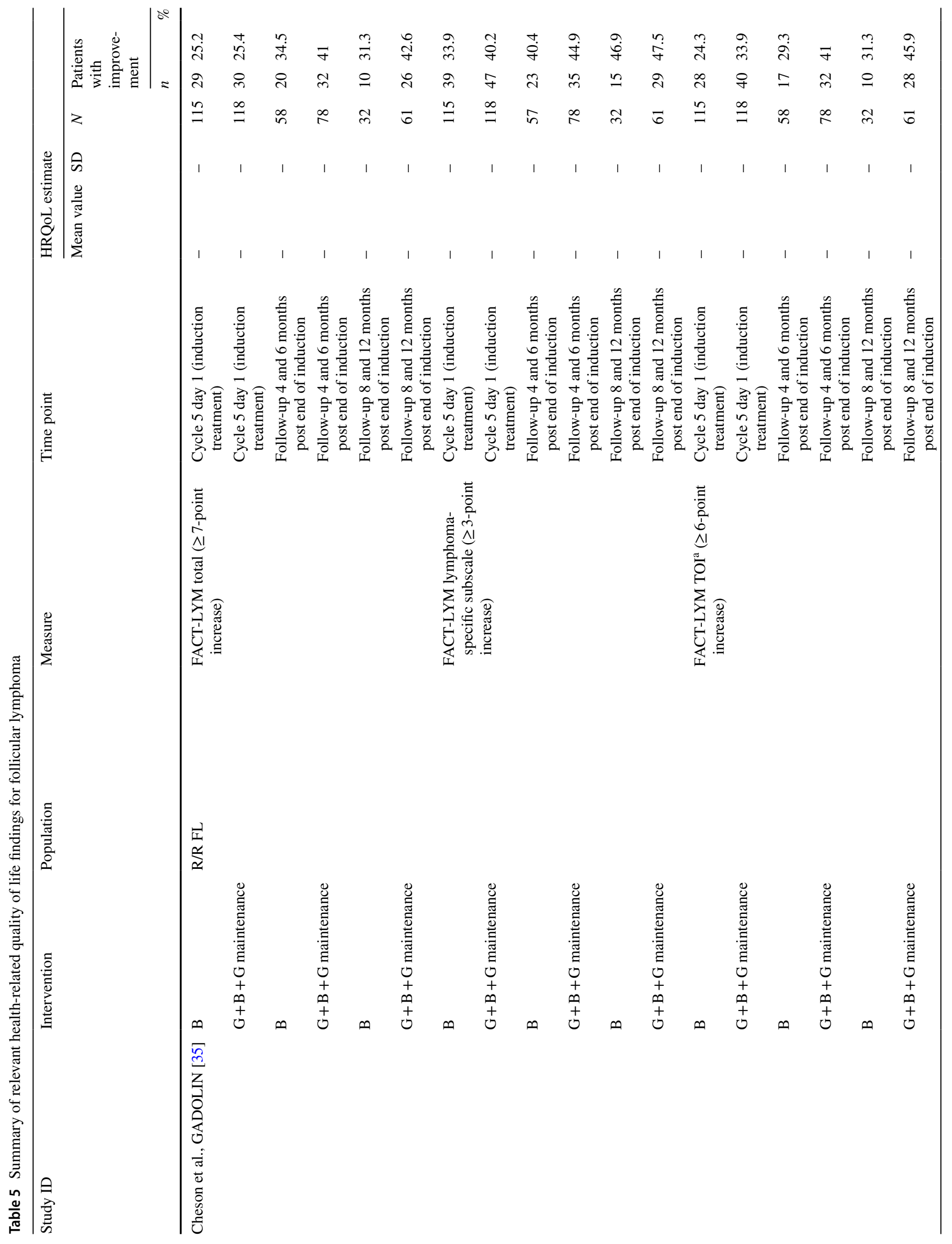




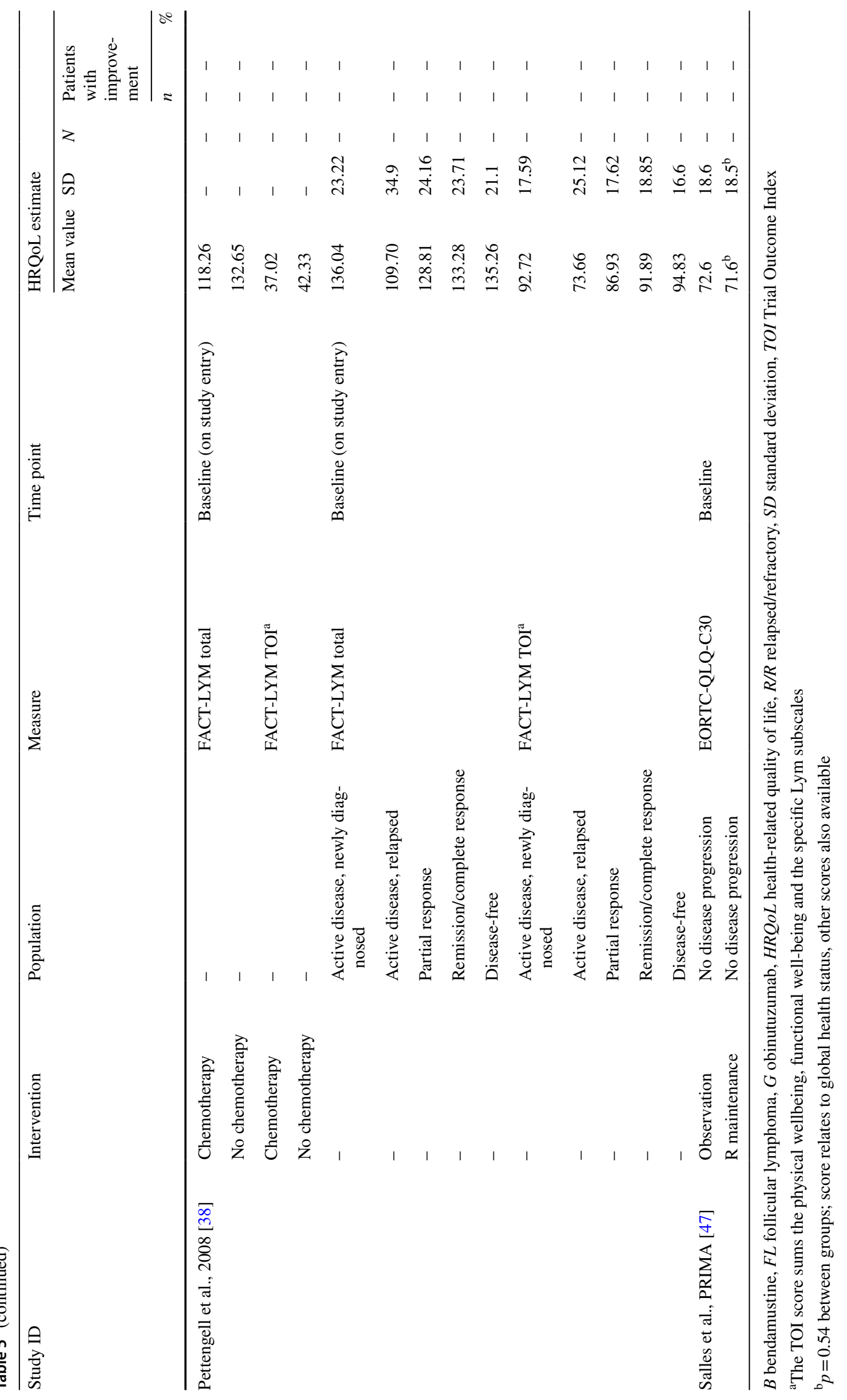


a national health care system (14 of the 25 studies). Other studies that specified a perspective utilised a US payer perspective (three studies $[15,19,26]$ ) or a societal perspective (one study [11]). Clinical trial data were the primary clinical input, with limited RWE data being used; however, given the increasing importance of RWE, and the efforts to collect these data, this will likely change in the future [39]. This could either be real-world cohort analyses (such as in Griffiths et al. [26]) or incorporating RWE data into models (such as in Blommestein et al. [21]). This current research offers a foundation upon which future assessments could be carried out.

In both first-line and $\mathrm{R} / \mathrm{R}$ populations, $\mathrm{R}+$ chemotherapy improved outcomes and QALYs and is cost effective (as per the $£ 30,000 /$ QALY threshold for UK studies). In the first-line FL setting, in the UK, the addition of R to chemotherapy (R-chemo) resulted in a cost per QALY of less than GBP£20,000 compared with chemotherapy alone (Table 3). In all FL studies that investigated maintenance treatments only (only FL studies are reported), in the first-line setting $\mathrm{R}$ maintenance was compared with observation, and the impact on the ICER was minimal (several estimates as low as AUD $\$ 15,000 / \mathrm{Q} A L Y$ ). In the R/R FL setting, $\mathrm{R}-\mathrm{CHOP}+\mathrm{R}$ maintenance versus $\mathrm{R}-\mathrm{CHOP}$ versus $\mathrm{CHOP}$ were conducted in UK and Finnish models (electronic supplementary Table 8) and were generally considered to be cost effective. However, in both first-line and R/R disease, further studies analyzing cost effectiveness are needed to strengthen the evidence base in this area.

Disease progression is associated with a substantial economic burden. Of note, one US study included a large sample size and estimated both costs and resource use of patients with R/R FL [30]. The study authors suggest that disease progression is associated with a fourfold increase in annual costs and more medical visits and laboratory procedures than non-progression $(\$ 30,890$ vs. $\$ 8704$, respectively), demonstrating that disease progression is a driver of both health care resources and costs for FL for health care systems globally.

Finally, there are limitations of note, both in terms of methods and the evidence identified. It is clear there is a marked dearth of evidence, which makes assessing the cost effectiveness of therapies, or even exploring modelling methodology, difficult. Studies reporting any indirect costs were not found and data on resource use were limited. Additionally, the lack of utility data, particularly in MZL, highlights the need for further research to draw comparisons and guide treatment decision making. There are also several limitations to the three reviews. First, publications that did not separate out FL and MZL were excluded. While there may be some additional papers that can offer further modelling insight, the authors feel this approach is clinically justified. FL and MZL have different etiologies; thus, patients may require different treatment approaches and can expect different outcomes. Therefore, while further modelling evidence may be available, the results of analyses that pool data on patients with different diseases will not be of importance to decision makers.

Given the limited published data found at the time of our review, there is a need for further research and a continued monitoring of the available evidence base in terms of both modelling strategy and overall cost effectiveness. This review offers the start of an evidence base that, to the authors' knowledge, was not previously available.

\section{Conclusions}

Overall, the addition of $\mathrm{R}$ to chemotherapy-based regimens, as well as R monotherapy, in maintenance improved clinical outcomes in a cost-effective way. Disease progression may be a driver of healthcare resource use, cost and patient HRQoL, however further research is required to confirm this. Despite treatments being available for patients for FL and MZL, there remains an unmet need to slow disease progression, improve quality of life for patients and improve all patient outcomes. Additional pharmacoeconomic analyses would help further our understanding of how best to assess the cost effectiveness of therapies in these disease areas. This in turn would aid healthcare decision making and work towards optimising therapies for patients with FL and MZL, within the constraints faced by healthcare providers.

Acknowledgements Medical writing support was provided by Iain Fotheringham, ICON plc, with funding from Janssen Pharmaceuticals.

Author Contributions NM: provided writing and technical support on SLR development and on the manuscript. JG: provided writing and technical support on SLR development and on the manuscript. BG: conducted evidence synthesis, including search strategy development, abstract and full-text screening, data validation and SLR report writing. Provided writing and technical support on the development of the manuscript. JQ: conducted evidence synthesis, including search strategy development, abstract and full-text screening consolidation, and also provided technical support on the SLR report. Provided writing and technical support on the development of the manuscript. PO'D: conducted evidence synthesis, including search strategy development, abstract and full-text screening, data extraction and technical support on the SLR report. Provided writing and technical support on the development of the manuscript. ChT: provided writing and technical support on SLR development and on the manuscript. LN: provided writing and technical support on SLR development and on the manuscript. CaT: provided writing and technical support on SLR development and on the manuscript. CL: provided writing and technical support on SLR development and on the manuscript.

Data Availability Statement The authors declare that the data supporting the findings of this study are available within the article and the supplementary files. All data were identified and assessed from the references listed in the study. 


\section{Compliance with Ethical Standards}

Conflict of interest Neerav Monga, Jamie Garside, Christina Loefgren, and Christoph Tapprich are employees of Janssen. Loretta Nastoupil and Catherine Thieblement received research support/honoraria from Janssen. Peter O'Donovan, Binu Gurung and Joan Quigley are employees of ICON plc and have received funding from Janssen to conduct/support this research.

Open Access This article is licensed under a Creative Commons Attribution-NonCommercial 4.0 International License, which permits any non-commercial use, sharing, adaptation, distribution and reproduction in any medium or format, as long as you give appropriate credit to the original author(s) and the source, provide a link to the Creative Commons licence, and indicate if changes were made. The images or other third party material in this article are included in the article's Creative Commons licence, unless indicated otherwise in a credit line to the material. If material is not included in the article's Creative Commons licence and your intended use is not permitted by statutory regulation or exceeds the permitted use, you will need to obtain permission directly from the copyright holder.To view a copy of this licence, visit http://creativecommons.org/licenses/by-nc/4.0/.

\section{References}

1. BMJ Best Practice. Non-Hodgkin's Lymphoma: classification 2016. Available at: http://bestpractice.bmj.com/best-practice/ monograph/312/basics/classification.html. Accessed 18 Oct 2016.

2. Chao MP. Treatment challenges in the management of relapsed or refractory non-Hodgkin's lymphoma-novel and emerging therapies. Cancer Manag Res. 2013;5:251-69. https://doi.org/10.2147/ cmar.s34273.

3. The Cochrane Collaboration. Cochrane Handbook for Systematic Reviews of Interventions Version 5.0.2 [updated September 2009]. The Cochrane Collaboration.

4. Hutton B, Salanti G, Caldwell DM, et al. The PRISMA extension statement for reporting of systematic reviews incorporating network meta-analyses of health care interventions: checklist and explanations. Ann Intern Med. 2015;162(11):777-84. https://doi. org/10.7326/m14-2385.

5. Centre for Reviews and Dissemination. Systematic Reviews: CRD's guidance for undertaking reviews in healthcare. 2009. https ://www.york.ac.uk/media/crd/Systematic_Reviews.pdf.

6. van Mastrigt GAPG, Hiligsmann M, Arts JJC, et al. How to prepare a systematic review of economic evaluations for informing evidence-based healthcare decisions: a five-step approach (part 1/3). Expert Rev Pharmacoecon Outcomes Res. 2016;16(6):689_ 704. https://doi.org/10.1080/14737167.2016.1246960.

7. Kulikov A, Rybchenko Y. Pharmacoeconomic study of the use of rituximab for subcutaneous administration in the treatment of follicular lymphoma. Val Health 2015;18(7):A463. https://doi. org/10.1016/j.jval.2015.09.1207.

8. Ray JA, Carr E, Lewis G, et al. An evaluation of the cost-effectiveness of rituximab in combination with chemotherapy for the first-line treatment of follicular non-hodgkin's lymphoma in the UK. Val Health. 2010;13(4):346-57. https://doi.org/10.111 1/j.1524-4733.2009.00676.x.

9. Papaioannou D, Rafia R, Rathbone J, et al. Rituximab for the first-line treatment of stage III-IV follicular lymphoma (review of Technology Appraisal No. 110): a systematic review and economic evaluation. Health Technol Assess 2012;16(37):1-253, iii-iv. http://doi.org/10.3310/hta16370.
10. Prica A, Chan K, Cheung M. Frontline rituximab monotherapy induction versus a watch and wait approach for asymptomatic advanced-stage follicular lymphoma: a cost-effectiveness analysis. Cancer. 2015;121(15):2637-45. https://doi.org/10.1002/ cncr.29372.

11. Hornberger J, Reyes C, Lubeck D, et al. Economic evaluation of rituximab plus cyclophosphamide, vincristine and prednisolone for advanced follicular lymphoma. Leukemia Lymph. 2008;49(2):227-36. https://doi.org/10.1080/10428190701769665.

12. Foster T, Miller JD, Boye ME, et al. Economic burden of follicular non-Hodgkin's lymphoma. Pharmacoeconomics. 2009;27(8):65779. https://doi.org/10.2165/11314820-000000000-00000.

13. Zucca E. Addition of rituximab to chlorambucil produces superior event-free survival in the treatment of patients with extranodal marginal-zone B-cell lymphoma: 5-year analysis of the IELSG-19 Randomized Study. J Clin Oncol. 2013;31(5):565-72.

14. Roche. MabTheraR (rituximab) for the first line maintenance treatment of follicular non-hodgkin's lymphoma: submission to the National Institute for Health and Clinical Excellence (NICE). London: NICE; 2010.

15. Hornberger J, Chien R, Friedmann M, et al. Cost-effectiveness of rituximab as maintenance therapy in patients with follicular non-Hodgkin lymphoma after responding to first-line rituximab plus chemotherapy. Leukemia Lymph. 2012;53(12):2371-7. https ://doi.org/10.3109/10428194.2012.694429.

16. Mervin MC. The cost effectiveness of rituximab maintenance therapy in patients with follicular lymphoma. Val Health 2016;19(3):A153. https://doi.org/10.1016/j.jval.2016.03.1606.

17. PBAC policy summary document (Department of Health). RITUXIMAB, solution for IV infusion, $100 \mathrm{mg}$ in $10 \mathrm{~mL}, 500 \mathrm{mg}$ in $50 \mathrm{~mL}$, Mabthera ${ }^{\circledR}$, Roche Products Pty Ltd. PBAC meeting 2014. https://www.pbs.gov.au/industry/listing/elements/pbacmeetings/psd/2014-07/rituximab-psd-07-2014.pdf.

18. Roche. MabTheraR (rituximab) for the treatment of relapsed follicular lymphoma: submission to the National Institute for Health and Clinical Excellence (NICE). London: NICE; 2007.

19. Hayslip JW, Simpson KN. Cost-effectiveness of extended adjuvant rituximab for US patients aged 65-70 years with follicular lymphoma in second remission. Clin Lymph Myeloma. 2008;8(3):166-70. https://doi.org/10.3816/CLM.2008.n.020.

20. Kasteng F, Erlanson M, Hagberg H, et al. Cost-effectiveness of maintenance rituximab treatment after second line therapy in patients with follicular lymphoma in Sweden. Acta Oncol. 2008;47(6):1029-36. https://doi.org/10.1080/028418608021200 28.

21. Blommestein HM, Issa DE, Pompen M, et al. Cost-effectiveness of rituximab as maintenance treatment for relapsed follicular lymphoma: results of a population-based study. Eur J Haematol. 2014;92(5):398-406. https://doi.org/10.1111/ejh.12264.

22. Sabater E, Lopez-Guillermo A, Rueda A, et al. Cost-effectiveness analysis of bendamustine plus rituximab as a first-line treatment for patients with follicular lymphoma in Spain. Appl Health Econ Health Policy. 2016;14(4):465-77. https://doi.org/10.1007/s4025 8-016-0243-4.

23. Pan-Canadian Oncology Drug Review (pCODR). Initial economic guidance report: obinutuzumab (gazyva) for follicular lymphoma. 2017. https://www.cadth.ca/sites/default/files/pcodr/pcodr_obinu tuzumab_gazyva_fl_in_egr.pdf.

24. Scottish Medicines Consortium. Obinutuzumab advice. Obinutuzumab $1,000 \mathrm{mg}$ concentrate for solution for infusion (Gazyvaro ${ }^{\circledR}$ ) SMC No. (1219/17), Roche Products Ltd. 2017. https://www.scott ishmedicines.org.uk/SMC_Advice/Advice/1219_17_obinutuzum ab_Gazyvaro/obinutuzumab_Gazyvaro.

25. Soini EJO, Martikainen JA, Nousiainen T. Treatment of follicular non-Hodgkin's lymphoma with or without rituximab: cost-effectiveness and value of information based on a 5-year follow-up. 
Ann Oncol. 2011;22(5):1189-97. https://doi.org/10.1093/annon c/mdq582.

26. Griffiths RI, Gleeson ML, Mikhael J, et al. Impact on medical cost, cumulative survival, and cost-effectiveness of adding rituximab to first-line chemotherapy for follicular lymphoma in elderly patients: an observational cohort study based on SEERmedicare. J Cancer Epidemiol. 2012;2012:978391. https://doi. org/10.1155/2012/978391.

27. Pan-Canadian Oncology Drug Review (pCODR). Final economic guidance report. Idelalisib (zydelig) for follicular lymphoma. 2016. https://www.cadth.ca/sites/default/files/pcodr/pcodr_idela lisib_zydelig_fl_fn_egr.pdf.

28. PBAC policy summary document. Obinutuzumab, solution for I.V. infusion $1000 \mathrm{mg}$ in $40 \mathrm{~mL}$, Gazyva ${ }^{\circledR}$, Roche Pty Ltd. PBAC meeting 2016. https://www.pbs.gov.au/industry/listing/elements/ pbac-meetings/psd/2016-11/files/obinutuzumab-psd-november2016.pdf.

29. Guzauskas GF, Masaquel A, Reyes C, et al. What is the costeffectiveness of obinutuzumab plus bendamustine followed by obinutuzumab monotherapy for the treatment of follicular lymphoma patients who relapse after or are refractory to a rituximabcontaining regimen in the US? Blood. 2016;128(22):3605.

30. Beveridge R, Satram-Hoang S, Sail K, et al. Economic impact of disease progression in follicular non-Hodgkin lymphoma. Leukemia Lymphoma. 2011;52(11):2117-23. https://doi. org/10.3109/10428194.2011.592623.

31. Danese MD, Reyes CM, Gleeson ML, et al. Estimating the population benefits and costs of Rituximab therapy in the United States from 1998 to 2013 using real-world data. Med Care. 2016;54(4):343-9. https://doi.org/10.1097/MLR.0000000000 000486

32. Shah GL, Winn A, Lin P-J, et al. Comparison of survival and costs of rituximab-based chemotherapy for initial therapy of follicular lymphoma in elderly patients. Blood. 2016;128(22):2354 .

33. Wang H, Aas E, Smith A, et al. Forecasting treatment costs of follicular lymphoma: a population-based discrete event simulation. Val Health 2016;19(3):A147. https://doi.org/10.1016/j. jval.2016.03.1575.

34. Berto P, Lopatriello S, Arcaini L, et al. Cost-effectiveness of rituximab in maintenance treatment of refractory or relapsing follicular non-Hodgkin lymphoma. Pharm Econ Ital Res Art 2007;9(1):9-19 (in Italian).

35. Cheson BD, Trask PC, Gribben JG, et al. Health-related quality of life and symptoms in patients with rituximab-refractory indolent non-Hodgkin lymphoma treated in the phase III GADOLIN study with obinutuzumab plus bendamustine versus bendamustine alone. Ann Hematol. 2017;96(2):253-9. https://doi.org/10.1007/ s00277-016-2878-5.

36. Zhou X, Wang J, Zhang J, et al. Symptoms and toxicity of rituximab maintenance relative to observation following immunochemotherapy in patients with follicular Lymphoma. Hematology. 2015;20(3):129-36. https://doi.org/10.1179/1607845414Y.00000 00179 .

37. Oerlemans $\mathrm{S}$, Issa DE, van den Broek EC, et al. Impact of therapy and disease-related symptoms on health-related quality of life in patients with follicular lymphoma: results of the population-based PHAROS-registry. Eur J Haematol. 2014;93(3):229-38. https:// doi.org/10.1111/ejh.12335.

38. Pettengell R, Donatti $\mathrm{C}$, Hoskin $\mathrm{P}$, et al. The impact of follicular lymphoma on health-related quality of life. Ann Oncol. 2008;19(3):570-6. https://doi.org/10.1093/annonc/mdm543.

39. Garrison LP Jr, Neumann PJ, Erickson P, et al. Using real-world data for coverage and payment decisions: the ISPOR real-world data task force report. Val Health. 2007;10(5):326-35. https://doi. org/10.1111/j.1524-4733.2007.00186.x.
40. Marcus R, Imrie K, Solal-Celigny P, et al. Phase III study of R-CVP compared with cyclophosphamide, vincristine, and prednisone alone in patients with previously untreated advanced follicular lymphoma. J Clin Oncol. 2008;26(28):4579-86. https:// doi.org/10.1200/jco.2007.13.5376.

41. Salles G, Mounier N, de Guibert S, et al. Rituximab combined with chemotherapy and interferon in follicular lymphoma patients: results of the GELA-GOELAMS FL2000 study. Blood. 2008;112(13):4824-31. https://doi.org/10.1182/blood-2008-04153189.

42. Herold M, Haas A, Srock S, et al. Rituximab added to firstline mitoxantrone, chlorambucil, and prednisolone chemotherapy followed by interferon maintenance prolongs survival in patients with advanced follicular lymphoma: an East German Study Group Hematology and Oncology Study. J Clin Oncol. 2007;25(15):1986-92. https://doi.org/10.1200/jco.2006.06.4618.

43. Hiddemann W, Kneba M, Dreyling M, et al. Frontline therapy with rituximab added to the combination of cyclophosphamide, doxorubicin, vincristine, and prednisone (CHOP) significantly improves the outcome for patients with advanced-stage follicular lymphoma compared with therapy with CHOP alone: results of a prospective randomized study of the German Low-Grade Lymphoma Study Group. Blood. 2005;106(12):3725-32. https://doi. org/10.1182/blood-2005-01-0016.

44. Foussard C, Mounier N, Hoof AV, et al. Update of the FL2000 randomized trial combining rituximab to CHVP-Interferon in follicular lymphoma (FL) patients (pts). J Clin Oncol. 2006;24(18 Suppl):7508. https://doi.org/10.1200/jco.2006.24.18_suppl.7508.

45. Marcus R, Imrie K, Belch A, et al. CVP chemotherapy plus rituximab compared with CVP as first-line treatment for advanced follicular lymphoma. Blood. 2005;105(4):1417-23. https://doi. org/10.1182/blood-2004-08-3175.

46. Rummel MJ, Niederle N, Maschmeyer G, et al. Bendamustine plus rituximab versus CHOP plus rituximab as first-line treatment for patients with indolent and mantle-cell lymphomas: an open-label, multicentre, randomised, phase 3 non-inferiority trial. Lancet. 2013;381(9873):1203-10. https://doi.org/10.1016/s0140 -6736(12)61763-2 (published Online First: 2013/02/26).

47. Salles G, Seymour JF, Offner F, et al. Rituximab maintenance for 2 years in patients with high tumour burden follicular lymphoma responding to rituximab plus chemotherapy (PRIMA): a phase 3, randomised controlled trial. Lancet. 2011;377(9759):42-51. https ://doi.org/10.1016/s0140-6736(10)62175-7.

48. van Oers MH, Van Glabbeke M, Giurgea L, et al. Rituximab maintenance treatment of relapsed/resistant follicular non-Hodgkin's lymphoma: long-term outcome of the EORTC 20981 phase III randomized intergroup study. J Clin Oncol. 2010;28(17):2853-8. https://doi.org/10.1200/jco.2009.26.5827.

49. Aw A, Coyle K, Bence-Bruckler I, et al. Bendamustine and rituximab versus conventional chemoimmunotherapy as a frontline treatment for patients with indolent B-Cell lymphoma: a costeffectiveness analysis. Blood. 2016;128(22):1186.

50. Hainsworth JD, Litchy S, Shaffer DW, Lackey VL, Grimaldi M, Anthony Greco F. Maximizing therapeutic benefit of rituximab: maintenance therapy versus re-treatment at progression in patients with indolent non-Hodgkin's lymphoma - a randomized phase ii trial of the Minnie Pearl Cancer Research Network. J Clin Oncol. 2005;23(6): 1088-95.

51. van Oers MH, Klasa R, Marcus RE, et al. Rituximab maintenance improves clinical outcome of relapsed/resistant follicular non-Hodgkin lymphoma in patients both with and without rituximab during induction: results of a prospective randomized phase 3 intergroup trial. Blood. 2006;108(10):3295-301. https://doi. org/10.1182/blood-2006-05-021113.

52. PBAC policy summary document. IDELALISIB oral tablet, 100 mg, 150 mg Zydelig ${ }^{\circledR}$, Gilead Sciences Pty Ltd. 2015. https 
://www.pbs.gov.au/industry/listing/elements/pbac-meetings/ psd/2015-11/files/idelalisib-follicular-lymphoma-psd-november2015.pdf.

53. Gopal AK, Kahl BS, de Vos S, et al. Mature follow up from a phase 2 study of PI3K-delta inhibitor idelalisib in patients with double (rituximab and alkylating agent)-refractory indolent B-cell non-hodgkin lymphoma (iNHL). Blood. 2014;124(21):1708.

54. PBAC policy summary document. IDELALISIB Oral tablet, 100 mg, 150 mg Zydelig ${ }^{\circledR}$, Gilead Sciences Pty Ltd. 2016. https ://www.pbs.gov.au/industry/listing/elements/pbac-meetings/ psd/2016-03/files/idelalisib-fl-psd-march-2016.pdf.
55. Sehn LH, Chua N, Mayer J, et al. Obinutuzumab plus bendamustine versus bendamustine monotherapy in patients with rituximab-refractory indolent non-Hodgkin lymphoma (GADOLIN): a randomised, controlled, open-label, multicentre, phase 3 trial. Lancet Oncol. 2016;17(8):1081-93. https://doi.org/10.1016/s1470 -2045(16)30097-3.

56. Soini EJ, Martikainen JA, Vihervaara V, et al. Economic evaluation of sequential treatments for follicular non-hodgkin lymphoma. Clin Ther. 2012;34(4):915.e2-925.e2. https://doi. org/10.1016/j.clinthera.2012.02.019.

\section{Affiliations}

\section{Neerav Monga ${ }^{1} \cdot$ Jamie Garside $^{2} \cdot$ Binu Gurung ${ }^{3} \cdot$ Joan Quigley $^{3} \cdot$ Peter O'Donovan $^{3} \cdot$ Christoph Tapprich $^{4}$. Loretta Nastoupil $^{5} \cdot$ Catherine Thieblemont $^{6} \cdot$ Christina Loefgren $^{7}$}

1 Global Market Access and Health Policy, Janssen Global Oncology, 19 Green Belt Dr., Toronto, ON M3C 1L9, Canada

2 HEMAR Janssen, High Wycombe, UK

3 ICON Plc, Abingdon, UK

4 Oncology Janssen, Neuss, Germany
5 Department of Lymphoma/Myeloma, The University of Texas MD Anderson Cancer Center, Houston, TX, USA

6 Hemato-Oncology, Hôpital Saint-Louis-APHP, Paris, France

7 Janssen R\&D, Raritan, NJ, USA 